\title{
Expression of BAG1 is associated with prognosis in kidney renal clear cell carcinoma based on bioinformatics
}

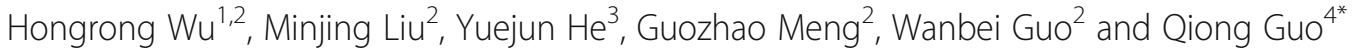

\begin{abstract}
Background: BCL2 associated Athano-Gene 1 (BAG1) has been described to be involved in the development and progression of cancer. But the role of BAG1 in kidney renal clear cell carcinoma (KIRC) has remained largely unknown.

Methods: We performed bioinformatic analysis of data from TCGA and GEO dataset. The role of BAG1 in KIRC was explored by Logistic and Cox regression model. The molecular mechanisms of BAG1 was revealed by GSEA.

Results: The current study found that the KIRC tumor samples have a low level of BAG1 mRNA expression compared to the matched normal tissues based on TCGA data and GEO databases. Low expression of BAG1 in KIRC was significantly associated with Sex, clinical pathological stage, tumor-node-metastasis (TNM) stage, hemoglobin levels, cancer status and history of neoadjuvant treatment. Kaplan-Meier survival analysis indicated that KIRC patients with BAG1 high expression have a longer survival time than those with BAG1 low expression $(p<0.000)$. Cox regression analysis showed that BAG1 remained independently associated with overall survival, with a hazard ratio (HR) of 1.75(Cl:1.05-2.90; $p=0.029)$. GSEA indicated that the signaling pathways including fatty acid metabolism and oxidative phosphorylation were differentially enriched in high BAG1 expression phenotype.

Conclusions: These findings suggested that BAG1 expression may act as a potential favorable prognostic marker and challenging therapeutic target.
\end{abstract}

Keywords: BAG1, Prognosis, KIRC, Fatty acid metabolism, Oxidative phosphorylation

\section{Background}

Clear cell renal cell carcinoma (ccRCC) is the most common, lethal subtype of kidney cancer [1,2]. There are five angiogenesis inhibitors approved by the United States Food and Drug Administration (FDA) for treatment of advanced and metastatic RCC, four of which VEGFR targeted tyrosine kinase inhibitors (TKIs) [2-4]. Despite the improved outcomes shown in the clinical trials of VEGF-targeted therapy, the length of response and

\footnotetext{
* Correspondence: guoqiong04@126.com
}

${ }^{4}$ Department of Urology, Hunan Provincial People's Hospital, The First

Affiliated Hospital of Hunan Normal University, No 61 West Liberation Road, Changsha 410005, Hunan, China

Full list of author information is available at the end of the article survival benefit of therapy varies considerably among patients [3]. Therefore, it is urgent to explore the molecular target for patient prognosis and treatment.

BAG1 is a multifunctional protein which associates with cellular processes: apoptosis, proliferation, cell survival, and motility [5]. In recent years, increasing evidence has indicated that the pivotal role of BAG1 involved in the pathogenesis or progression of tumor [6-9]. Over-expression of BAG1 in head and neck squamous cell carcinomas (HNSCC) is associated with cisplatin-resistance [10]. BAG1 act as a potential prognostic marker in node-negative breast carcinoma [11].

(c) The Author(s). 2021 Open Access This article is licensed under a Creative Commons Attribution 4.0 International License, which permits use, sharing, adaptation, distribution and reproduction in any medium or format, as long as you give appropriate credit to the original author(s) and the source, provide a link to the Creative Commons licence, and indicate if changes were made. The images or other third party material in this article are included in the article's Creative Commons licence, unless indicated otherwise in a credit line to the material. If material is not included in the article's Creative Commons licence and your intended use is not permitted by statutory regulation or exceeds the permitted use, you will need to obtain permission directly from the copyright holder. To view a copy of this licence, visit http://creativecommons.org/licenses/by/4.0/ The Creative Commons Public Domain Dedication waiver (http://creativecommons.org/publicdomain/zero/1.0/) applies to the data made available in this article, unless otherwise stated in a credit line to the data. 
However, to our best knowledge, the role of BAG1 in KIRC has not been described for the present.

In this study, we illustrate the prognostic value of BAG1 expression in KIRC using The Cancer Genome Atlas (TCGA) and gene expression omnibus (GEO) databases, the result shows that BAG1 expression associated with a well prognosis in patients with KIRC. At the same time, we conducted Gene Set Enrichment Analysis (GSEA) tool to identify the BAG1-related enriched signaling pathways in KIRC.

\section{Methods}

\section{TCGA and GEO data}

The gene expression (Workflow Type: level 3 HTSeqFPKM) of 611 samples including 539 tumor samples, 72 normal samples and clinical data were collected from The Cancer Genome Atlas (TCGA). Boxplots method was used to test the discrete variables in KIRC tumor samples [12]. Finally, The RNA-Seq expression data of 449 patients with KIRC and clinical data were retained for further analysis (Table 1).

We also downloaded another gene expression data of renal tumors from the GEO database (the accession number: GSE105288) to provide further evidence for comparing gene expression between normal and tumor groups in KIRC patients.

\section{Gene expression analysis}

BAG1 mRNA expression levels were extracted from the TCGA and GEO database using tidyverse package that is an opinionated collection of $\mathrm{R}$ packages designed for data science. Secondly, we employed ggplot2 and boxplot $\mathrm{R}$ packages to visualize expression levels of a single gene in different situation.

\section{GEPIA (Gene Expression Profiling Interactive Analysis)}

GEPIA: a web server for cancer and normal gene expression profiling and interactive analyses [13].GEPIA performs overall survival (OS) or disease-free survival (DFS, also called relapse-free survival and RFS) analysis based on gene expression [13]. Thus, we employ online GEPIA tool to analyze the survival of KIRC patients.

\section{Gene Set Enrichment Analysis (GSEA)}

GSEA is a computational method that determines whether an a priori defined set of genes shows statistically significant, concordant differences between two biological states [14]. This method using the GSEA tool was the same as those described by Wuhongr et al. [15]. In the present work, All the tumor samples were ranked according to the expression level of BAG1. The expression level was divided into highand low- groups according to the median value of BAG1. Gene set permutations was set at 1000 times.
Table 1 Kidney renal clear cell carcinoma patient characteristics from TCGA data

\begin{tabular}{|c|c|c|c|}
\hline Clinical characteristics & & Total (449) & $\%$ \\
\hline Age at diagnosis(y) & & $60(26-90)$ & \\
\hline \multirow[t]{2}{*}{ Sex } & male & 289 & 64.4 \\
\hline & female & 160 & 35.6 \\
\hline \multirow[t]{6}{*}{ Grade } & G1 & 12 & 2.7 \\
\hline & G2 & 189 & 42.4 \\
\hline & G3 & 173 & 38.8 \\
\hline & G4 & 70 & 15.7 \\
\hline & Gx & 2 & 0.4 \\
\hline & NA & 3 & \\
\hline \multirow[t]{4}{*}{ Cancer status } & With tumor & 126 & 29.5 \\
\hline & Tumor free & 296 & 69.3 \\
\hline & Discrepancy & 5 & 1.2 \\
\hline & NA & 22 & . \\
\hline \multirow[t]{5}{*}{ Stage } & 1 & 219 & 49.1 \\
\hline & $\|$ & 45 & 10.1 \\
\hline & III & 106 & 23.8 \\
\hline & IV & 76 & 17 \\
\hline & NA & 3 & \\
\hline \multirow[t]{4}{*}{ Tumor size } & $\mathrm{T} 1$ & 225 & 50.1 \\
\hline & $\mathrm{T} 2$ & 56 & 12.5 \\
\hline & $\mathrm{T} 3$ & 159 & 35.4 \\
\hline & $\mathrm{T} 4$ & 9 & 2 \\
\hline \multirow[t]{3}{*}{ Lymph nodes } & Negative & 199 & 93.4 \\
\hline & Positive & 14 & 6.6 \\
\hline & NA & 236 & \\
\hline \multirow[t]{3}{*}{ Distant metastasis } & Negative & 366 & 83.2 \\
\hline & Positive & 74 & 16.8 \\
\hline & NA & 9 & \\
\hline \multirow[t]{4}{*}{ Hemoglobin result } & Elevated & 4 & 1 \\
\hline & Low & 227 & 59 \\
\hline & Normal & 154 & 40 \\
\hline & NA & 64 & \\
\hline \multirow[t]{2}{*}{ History of neoadjuvant treatment } & No & 435 & 96.9 \\
\hline & Yes & 14 & 3.1 \\
\hline \multirow[t]{4}{*}{ Serum calcium result } & Elevated & 8 & 2.6 \\
\hline & Low & 176 & 56.2 \\
\hline & Normal & 129 & 41.2 \\
\hline & NA & 136 & \\
\hline
\end{tabular}

The nominal $P$ value and normalized enrichment score (NES) were used to sort the pathways enriched in each phenotype. 


\section{Statistical analysis}

All statistical analyses were performed out using the software R (3.5.1). The relationship between BAG1 as a continuous variable and clinical characteristics were explored by the Wilcoxon signed-rank test or the KruskalWallis test. Association of BAG1 as a categorical variable with the clinicopathological characteristics of KIRC was explored through logistic regression. The cutoff value of BAG1 expression was obtained by the median expression level. Based on the cutoff value, the clinical tumor samples were stratified into "low" and "high" groups. Comparison of Kaplan-Meier survival between groups was performed using the log-rank statistics. Both univariate and multivariate analyses were performed to evaluate the prognostic significance of BAG1 expression in KIRC tumor patients.

\section{Results}

\section{KIRC patients' characteristics}

The clinical information and BAG1 expression data of 449 KIRC patients from TCGA were merged into a document. Table 1 indicated that the median age at diagnosis is 60 years old. Female patients accounted for $35.6 \%(n=160)$, male in $64.4 \%(n=289)$. The clinical stage I was found in 219 patients (49.1\%), stage II in 45 (10.1\%), stage III in 106 (23.8\%), stage IV in 76 (17\%). 14 out of $213(6.6 \%)$ cases had lymph node metastases. Distant metastases in 74 accounted for $16.8 \%$. The median follow-up duration for subjects alive at last contact was 38.6 months (range 0-149 months).

We also collected gene expression data from renal tumors and normal kidneys in GEO data (series GSE105288) to detect the difference in BAG1 expression levels between normal and tumor group. The GSE105288 data include 9 normal samples,10 primary renal cell carcinoma samples and 35 metastasis renal cell carcinoma samples.

\section{Downregulation of BAG1 in KIRC tissues}

KIRC tissues $(N=539)$ exhibited lower levels of BAG1 mRNA expression $(p<0.001)$ than the corresponding normal tissues $(N=72)$ in TCGA data (Fig. 1a). To further strengthen the evidence differences in BAG1 expression level between tumor and normal tissues, we retrieved another gene expression data from GEO (series number: GSE105288). Figure 1b showed that the BAG1 expression was also reduced in the tumor tissues of KIRC $(N=35, p<0.011)$ compared with the normal tissues $(N=12)$.

\section{Association with BAG1 expression and pathologic variables}

A total of 499 KIRC samples with BAG1 expression data and patient's clinical pathological parameters from
TCGA were analyzed. Unlike some previous studies that have suggested BAG1 may be associated with a poor clinical features [16, 17], we found that its expression as a continuous variable showed a significant inverse correlation with the clinical characteristics in KIRC, such as stage (stage I vs. stage IV $p<0.001)$, tumor size $(p<$ $0.001)$, Sex $(p<0.001)$, grade $(p<0.001)$, serum hemoglobin level $(p=0.018)$, cancer status $(p<0.01)$, lymph node metastasis $(p=0.04)$ and distant metastasis $(p<0.001)$ (Fig. 2a-i). To further characterize this association between BAG1 and this clinical pathologic feature, We used logistic regression to explore the association of BAG1 expression as a categorical variable based on the median value of gene expression level with the clinicopathological characteristics of KIRC. Table 2 showed that there was also a significant correlation between BAG1 and tumor size $(p<0.001)$, lymph node metastasis $(p<0.01)$, distant metastasis $(p<0.001)$, clinical stage $(p<0.000)$, grade $(p<0.000)$, Sex $(p<0.01)$, hemoglobin levels $(p<0.01)$ and cancer status $(p<0.001)$.

\section{Survival outcomes and multivariate analysis}

As shown in Fig. 1c and d, KIRC patients with higher BAG1 expression experienced significantly favorable overall survival $(\mathrm{OS})(p<0.001)$ and disease-free survival (DFS) $(p<0.001)$ than those with lower BAG1 expression through GEPIA tool. Table 3a showed that the univariate analysis using Cox regression indicated that high BAG1 expression correlated significantly with a good OS (hazard ratio [HR]: 2.11; 95\% confidence interval $[\mathrm{CI}]: 1.5-2.97 ; p<0.001)$. Other variables associated with overall survival include Sex, clinical grade, stage, cancer status, and tumor size. At multivariate analysis, BAG1 remained independently associated with overall survival, with a $\mathrm{HR}$ of $1.75(\mathrm{CI}$ : 1.05-2.90, $p=0.029)$, along with tumor size, stage, lymph nodes and distant metastasis. Together, the results indicate that elevated BAG1 expression is a good prognosis for KIRC patients.

\section{The BAG1-associated pathways analyzed by GSEA}

To search the biological mechanism of BAG1 in KIRC, we performed the GSEA to identify the tumorassociated pathways or gene sets that altered between the patients with low BAG1 expression and those with high BAG1 expression. We selected the most significantly enriched signaling pathways based on those principles such as their normalized enrichment score (NES), nominal $p$ value $<0.05$ and FDR $<0.25$. Figure 3 showed that two signaling pathways (fatty acid metabolism and oxidative phosphorylation) are differentially enriched in high BAG1 expression group. 


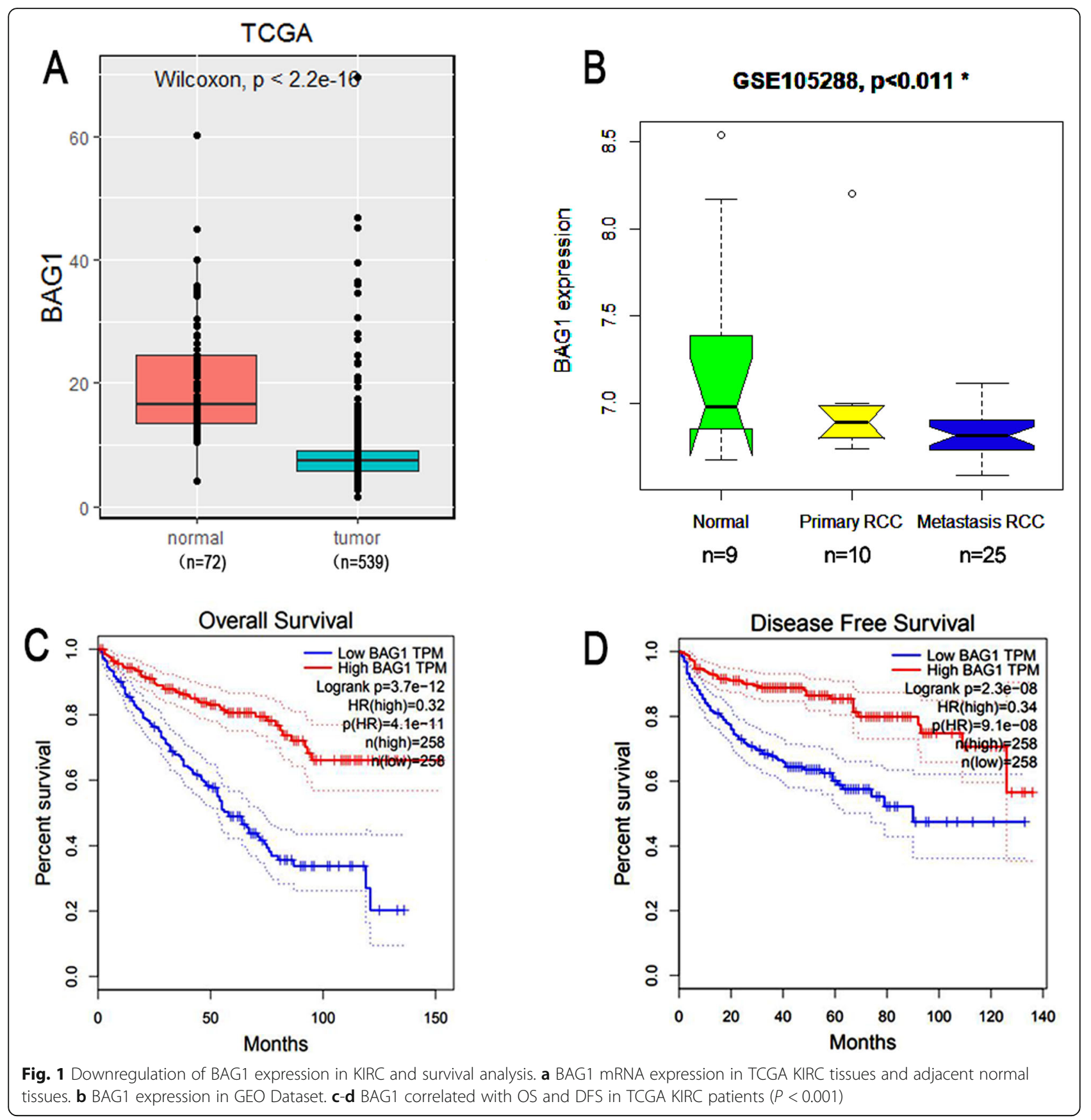

\section{Discussion}

In the study, we demonstrated that the BAG1 mRNA expression levels were downregulated in KIRC patients compared to the normal through TCGA and GEO data (Fig. 1a, b). This result suggests that BAG1 may act as an inducible tumor suppressor in KIRC. However, our finding is interestingly inconsistent with other previous studies concerning the biological function of BAG1 [6, 10, 18-20].

In general, The oncogene BCL2 is a membrane protein that blocks a step in a pathway leading to apoptosis or programmed cell death [21]. BAG1 enhances the antiapoptotic effects of BCL2 and act as a link between growth factor receptors and anti-apoptotic mechanisms [22]. Overexpression of BAG-1 has closely related to cell differentiation and TNM stage in esophageal cancer and its downregulation inhibits the proliferation and invasion of human esophageal carcinoma cells [16]. Thus, the BAG1 was considered to be a most commonly activated oncogene. However, inconsistent with other studies, our observations showed that low BAG1 expression in KIRC correlated significantly with aggressive tumor 


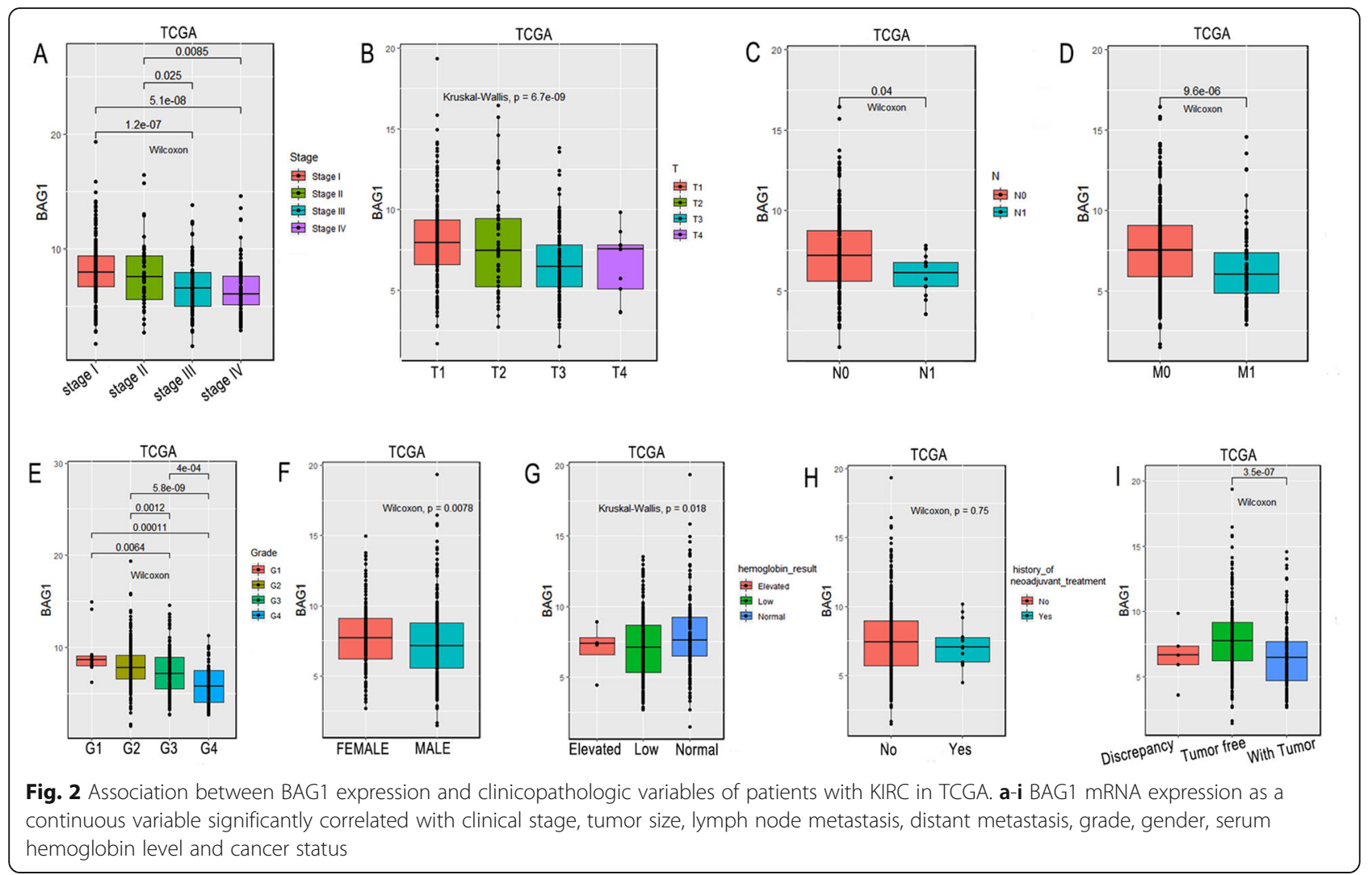

progression toward more malignant phenotypes including clinical stage, grade, tumor size, lymph node metastasis and distant metastasis (Table 2 and Fig. 2). these findings strongly suggested that BAG1 was a tumor suppressor gene and an attractive therapeutic target to inhibit cancer progression in KIRC. Therefore, these studies suggest that the BAG1 gene may have a dual role in tumorigenesis and need further study to support our findings.
In this study, KIRC patients with higher BAG1 expression have a significantly better overall survival (OS) and disease-free survival (DFS) than those with lower BAG1 expression (Fig. 1c, d). The univariate analysis and multivariate analysis using Cox regression show that BAG1 expression is a good prognosis for KIRC patients. This result indicated that BAG1 may be a prognostic marker and promising therapeutic target for KIRC patients. In addition, the present

Table 2 Association of $B A G 1^{a}$ expression with the clinicopathological characteristics of KIRC using logistic regression

\begin{tabular}{lll}
\hline Feature & OR (Cl) & $\boldsymbol{p}$ value \\
\hline Tumor size & $1.84(1.50 \sim 2.26)$ & $0.000^{* * *}$ \\
Lymph node metastasis & $4.76(1.04 \sim 21.81)$ & $0.044^{*}$ \\
Distant metastasis & $3.71(2.10 \sim 6.55)$ & $0.000^{* * *}$ \\
Clinical stage & $1.72(1.45 \sim 2.04)$ & $3.64 e^{-10^{* * *}}$ \\
Grade & $2.18(1.67 \sim 2.85)$ & $0.000^{* * *}$ \\
Age (continuous variant) & & 0.524 \\
Gender (Male vs. Female) & $1.88(1.27 \sim 2.79)$ & $0.001^{* *}$ \\
Hemoglobin result & $0.57(0.39 \sim 0.85)$ & $0.006^{* *}$ \\
History of neoadjuvant treatment (Yes vs. No) & & 0.594 \\
Cancer status & $2.73(1.76 \sim 4.23)$ & $0.000^{* * *}$ \\
Serum calcium (Low vs. High) & & 0.186 \\
\hline
\end{tabular}

${ }^{a}$ Categorical dependent variable, greater or less than the median expression level

${ }^{*}: p<0.05,{ }^{* *}: p<0.01,{ }^{* * *}: p<0.001$ 
Table 3 Associations with overall survival and clinicopathologic characteristics in TCGA patients using Cox regression. b. Multivariate survival model after variable selection

\begin{tabular}{|c|c|c|}
\hline Clinicopathologic variable & $\mathrm{HR}(95 \% \mathrm{Cl})$ & $p$-value \\
\hline \multicolumn{3}{|l|}{ a } \\
\hline Age (continuous) & $1.03(1.02-1.05)$ & $0.000 * * *$ \\
\hline BAG1 expression (Low vs. High) & $2.11(1.5-2.97)$ & $0.000^{* * *}$ \\
\hline Grade & $2.25(1.83-2.77)$ & $0.000 * * *$ \\
\hline Stage & $1.94(1.72-2.22)$ & $0.000^{* * *}$ \\
\hline Cancer Status (tumor free vs. with tumor) & $4.92(3.52-6.91)$ & $0.000 * * *$ \\
\hline Tumor size & $1.90(1.61-2.31)$ & $0.000^{* * *}$ \\
\hline Lymph nodes (positive vs. negative) & $3.41(1.69-6.90)$ & $0.000^{* * *}$ \\
\hline Distant metastasis (positive vs. negative) & $4.43(3.18-6.61)$ & $0.000^{* * *}$ \\
\hline Gender (male vs. Female) & $0.91(0.65-1.31)$ & 0.576 \\
\hline hemoglobin result (Low vs. Normal) & $0.45(0.30-0.66)$ & $0.000^{* * *}$ \\
\hline history of neoadjuvant treatment (Yes vs. No) & $2.37(1.21-4.66)$ & $0.012 *$ \\
\hline Serum calcium (Low vs. High) & $1.21(0.81-1.61)$ & 0.431 \\
\hline \multicolumn{3}{|l|}{$b$} \\
\hline Tumor size & $1.25(0.72-2.17)$ & 0.417 \\
\hline Lymph nodes (positive vs. negative) & $1.71(0.78-3.73)$ & 0.175 \\
\hline Distant metastasis (positive vs. negative) & $1.97(0.79-4.91)$ & 0.145 \\
\hline Stage & $1.25(0.67-2.32)$ & 0.478 \\
\hline BAG1 expression (Low vs. High) & $1.75(1.05-2.90)$ & $0.029^{*}$ \\
\hline
\end{tabular}

${ }^{*}: p<0.05, * *: p<0.01, * * *: p<0.001$

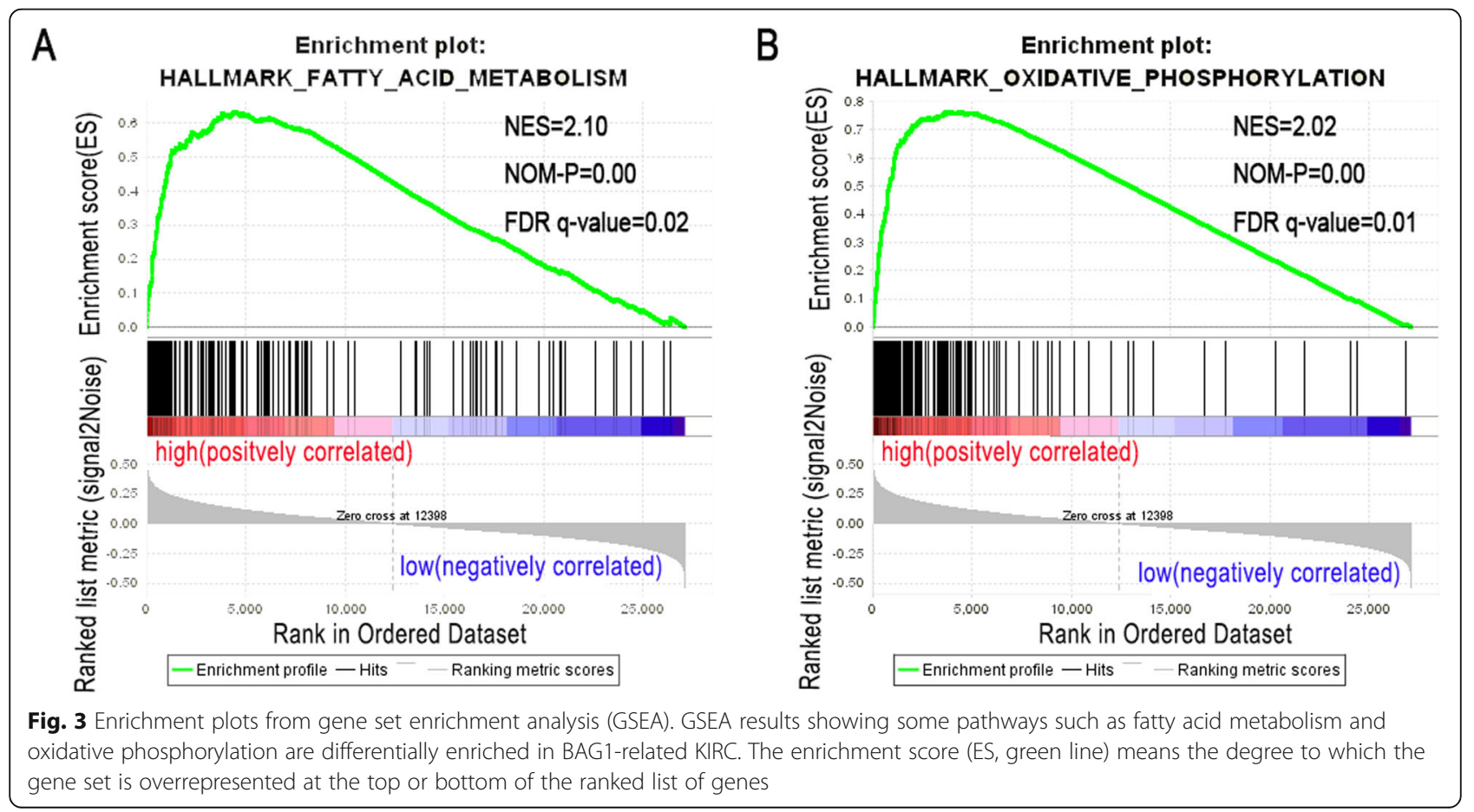


study also indicated that BAG1 has a dual role in tumorigenesis to some degree.

We found that the dual role of BAG1 may be due to its subcellular localization by searching associated references. For example, positive cytoplasmic BAG1 had a trend for favorable outcome following radical resection of pancreatic head cancer [23]. Nuclear BAG1 was highly expressed in $\mathrm{HCC}$, and this overexpression was correlated with the poor prognosis as well as histological grade, suggesting a prognostic value of BAG1 in HCC [24]. Thus, we infer that BAG1 may inhibit cancer progression in KIRC vial localizing in the cytoplasm.

To explore the molecular mechanisms of BAG1 in KIRC, we conducted the GSEA tool to dig data mining for KIRC based on gene expression datasets from TCGA.GSEA identified that two signaling pathways (fatty acid metabolism and oxidative phosphorylation) are differentially enriched (Fig. 3). The general consensus is that these pathways take place in the mitochondria membrane $[25,26]$. We therefore assumed that the subcellular location of BAG1 playing a role in KIRC is also located in the mitochondria membrane.

The present study has some limitations due to its pure bioinformatic method. The BAG1 expression level may not well represent its encoding protein level. Therefore, further experiments are required to assess the roles of BAG1 in KIRC.

\section{Conclusion}

This study indicated that BAG1 expression is a favorable prognosis for KIRC patient and provides insight into the treatment of KIRC that BAG1 may serve as a potential therapeutic target in regulating several signaling pathways.

\section{Abbreviations \\ BAG1: BCL2 associated Athano-Gene 1; KIRC: Kidney renal clear cell carcinoma; TCGA: The Cancer Genome Atlas; GEO: Gene expression omnibus; GSEA: Gene Set Enrichment Analysis; TNM: Tumor node metastasis; ccRCC: Clear cell renal cell carcinoma; FDA: Food and Drug Administration; TKIs: Tyrosine kinase inhibitors; HNSCC: Head and neck squamous cell carcinomas; OS: Overall survival; DFS: Disease-free survival; GEPIA: Gene Expression Profiling Interactive Analysis}

\section{Acknowledgements}

We would like to thank TCGA and GEO databases for providing high-quality clinical data on KIRC diseases.

\section{Authors' contributions \\ HRW. Designed this study and carried out data acquisition and analysis. $H R W, M J L, Y J H, G Z M, W B G$, and QG wrote the manuscript and contributed to preparing and making figures and tables. All authors read and approved the final manuscript.}

\section{Funding}

This work was supported by the Changsha Yaxiang Biological Technology Co., Ltd., topic name: The study of prognostic role of BAG1 in kidney renal clear cell carcinoma, project number: 20180612. In current study, the company provides a high-performance computer for data analysis, the funding body played no role in the design of the study and collection, analysis, and interpretation of data and in writing the manuscript.

\section{Availability of data and materials}

Data collections and processions were performed according to policies of TCGA project (https://portal.gdc.cancer.gov/) and GEO (accession number: GSE105288). The public access to the databases is open.

\section{Ethics approval and consent to participate}

The study was approved by the Ethics Committee of the Affiliated Hospital of Guangdong Medical University (Zhanjiang, 524001, Guangdong, China) and Xiangnan University (Chenzhou, Hunan Province, China).

\section{Consent for publication}

Not applicable.

\section{Competing interests}

The authors declare that they have no competing interests.

\section{Author details}

'Department of Pathology, the Affiliated Hospital of Guangdong Medical University, Zhanjiang 524001, Guangdong, China. ${ }^{2}$ Institute of Basic Disease Sciences, XiangNan University, Chenzhou, Hunan Province, China. ${ }^{3}$ Department of Supervision, Baiyun International Airport Customs' Inspection, Guangzhou, China. ${ }^{4}$ Department of Urology, Hunan Provincial People's Hospital, The First Affiliated Hospital of Hunan Normal University, No 61 West Liberation Road, Changsha 410005, Hunan, China.

Received: 23 September 2020 Accepted: 3 February 2021 Published online: 13 February 2021

\section{References}

1. Wei EY, Hsieh JJ. A river model to map convergent cancer evolution and guide therapy in RCC. Nat Rev Urol. 2015;12:706.

2. Funakoshi T, Lee $\mathrm{C}-\mathrm{H}, \mathrm{H}$ sieh JJ. A systematic review of predictive and prognostic biomarkers for VEGF-targeted therapy in renal cell carcinoma. Cancer Treat Rev. 2014:40:533-47.

3. Motzer RJ, Hutson TE, Tomczak P, et al. Sunitinib versus interferon Alfa in metastatic renal-cell carcinoma. N Engl J Med. 2007;356:115-24.

4. Escudier B, Pluzanska A, Koralewski P, et al. Bevacizumab plus interferon alfa2a for treatment of metastatic renal cell carcinoma: a randomised, doubleblind phase III trial. Lancet. 2007;370:2103-11.

5. Takayama S, Sato T, Krajewski S, et al. Cloning and functional analysis of BAG-1: a novel Bcl-2-binding protein with anti-cell death activity. Cell. 1995; 80:279-84.

6. Papadakis ES, Reeves T, Robson NH, Maishman T, Packham G, Cutress RI. BAG-1 as a biomarker in early breast cancer prognosis: a systematic review with meta-analyses. Br J Cancer. 2017;116:1585.

7. Cutress Rl, Townsend PA, Brimmell M, Bateman AC, Hague A, Packham G. BAG-1 expression and function in human cancer. Br J Cancer. 2002;87:834.

8. Townsend PA, Dublin E, Hart IR, et al. BAG-i expression in human breast cancer: interrelationship between BAG-1 RNA, protein, HSC70 expression and clinico-pathological data. J Pathol. 2002;197:51-9.

9. Southern SL, Collard TJ, Urban BC, et al. BAG-1 interacts with the p50-p50 homodimeric NF-KB complex: implications for colorectal carcinogenesis. Oncogene. 2011;31:2761

10. Liu S, Ren B, Gao H, et al. Over-expression of BAG-1 in head and neck squamous cell carcinomas (HNSCC) is associated with cisplatin-resistance. J Transl Med. 2017;15:189.

11. Davidson B, Valborg Reinertsen K, Trinh D, Reed W, Bohler PJ. BAG-1/SODD, HSP70, and HSP90 are potential prognostic markers of poor survival in node-negative breast carcinoma. Hum Pathol. 2016;54:64-73.

12. Kruppa J, Jung K. Automated multigroup outlier identification in molecular high-throughput data using bagplots and gemplots. BMC Bioinformatics. 2017;18:232.

13. Tang Z, Li C, Kang B, Gao G, Li C, Zhang Z. GEPIA: a web server for cancer and normal gene expression profiling and interactive analyses. Nucleic Acids Res. 2017;45:W98-w102.

14. Subramanian A, Tamayo P, Mootha VK, et al. Gene set enrichment analysis: a knowledge-based approach for interpreting genome-wide expression profiles. Proc Natl Acad Sci. 2005;102:15545-50. 
15. Wu H, Zhang J. Decreased expression of TFAP2B in endometrial cancer predicts poor prognosis: a study based on TCGA data. Gynecol Oncol. 2018; 149:592-7.

16. Huang $B$, Zhou H, Lang X, Liu Z, Xiong F, Wang S. Expression of BAG-1 is closely related to cell differentiation and TNM stage in esophageal cancer and its downregulation inhibits the proliferation and invasion of human esophageal carcinoma cells. Oncol Rep. 2014;32:1441-6.

17. Yang J, Cai Z, Du W, Li J, Chen T, Xu Y. The relationship between bag-1 and gastric cancer clinicopathologic characteristic. Chin-Ger J Clin Oncol. 2011; 10:459.

18. Jodoin R, Perreault J-P, Bisaillon M. Abstract A08: A 5'UTR RNA G-Quadruplex structure affects both the cap-dependent and independent translation of BAG-1, an mRNA involved in colorectal cancer. AACR; 2017.

19. Shen Z, Li Y, Zhao C, Wang F. Zhou R and Chen G: miR-494-BAG-1 axis is involved in cinobufacini-induced cell proliferation and apoptosis in gastric cancer. Mol Med Rep. 2018;17:7435-41.

20. Cato L, Neeb A, Sharp A, et al. Development of bag-1L as a therapeutic target in androgen receptor-dependent prostate cancer. Elife. 2017;6: e27159.

21. Galvan V, Brandimarti R, Munger J, Roizman B. BCl-2 blocks a caspasedependent pathway of apoptosis activated by herpes simplex virus 1 infection in HEp-2 cells. J Virol. 2000;74:1931-8.

22. Wang HG, Takayama S, Rapp UR, Reed JC. BCl-2 interacting protein, BAG-1, binds to and activates the kinase Raf-1. Proc Natl Acad Sci U S A. 1996;93: 7063-8.

23. van der Zee JA, Ten Hagen TL, Hop WC, et al. BCl-2 associated anthanogen1 (Bag-1) expression and prognostic value in pancreatic head and periampullary cancer. Eur J Cancer. 2013;49:323-8.

24. Ni W, Chen B, Zhou G, et al. Overexpressed nuclear BAG-1 in human hepatocellular carcinoma is associated with poor prognosis and resistance to doxorubicin. J Cell Biochem. 2013;114:2120-30.

25. Liberman EA, Topaly VP, Tsofina LM, Jasaitis AA, Skulachev VP. Mechanism of coupling of oxidative phosphorylation and the membrane potential of mitochondria. Nature. 1969;222:1076-8.

26. Xu, Jing, Nie, et al. Down-regulated energy metabolism genes associated with mitochondria oxidative phosphorylation and fatty acid metabolism in viral cardiomyopathy mouse heart. Mol Biol Rep. 2011;38:4007-13.

\section{Publisher's Note}

Springer Nature remains neutral with regard to jurisdictional claims in published maps and institutional affiliations.

Ready to submit your research? Choose BMC and benefit from:

- fast, convenient online submission

- thorough peer review by experienced researchers in your field

- rapid publication on acceptance

- support for research data, including large and complex data types

- gold Open Access which fosters wider collaboration and increased citations

- maximum visibility for your research: over $100 \mathrm{M}$ website views per year

At $\mathrm{BMC}$, research is always in progress.

Learn more biomedcentral.com/submissions 